\title{
Concurrent validity of Myotest for assessing explosive strength indicators in countermovement jump
}

\author{
Vladimír Hojka*, James J. Tufano, Tomáš Malý, Petr Šţastný, Radim Jebavý, Jan Feher, František \\ Zahálka, and Tomáš Gryc
}

Faculty of Physical Education and Sport, Charles University, Prague, Czech Republic

Copyright: (C) 2018 V. Hojka et al. This is an open access article licensed under the Creative Commons Attribution License (http://creativecommons.org/licenses/by/4.0/).

\begin{abstract}
Background: Previous research has determined the validity and reliability of accelerometer-based devices, but the findings are not consistent. Objective: The purpose of this study was to determine the validity of an accelerometer (Myotest PRO) for measuring explosive strength indicators (jump height, peak force, peak velocity, and peak power) during the countermovement jump. Methods: Thirty-three university students (22 males and 11 females; $178.6 \pm 5.6 \mathrm{~cm}, 69.3 \pm 6.5 \mathrm{~kg}, 21.8 \pm 1.7$ years) performed five individual countermovement jumps. Jump height was derived from an accelerometer (Myotest, frequency $200 \mathrm{~Hz}$ ), optic timing system (Optojump) and from a force plate (Kistler, frequency $800 \mathrm{~Hz}$ ) using both flight time and force impulse algorithms. Peak force, peak velocity, and peak power were calculated by the accelerometer and force plate. Results: The Myotest resulted in systematic bias, overestimating jump height by $8.0 \pm 2.1 \mathrm{~cm}(p<.001)$ compared to force impulse algorithm; flight time algorithm by $5.5 \pm 2.0 \mathrm{~cm}(p<.001)$ using the force plate and by $5.9 \pm 2.0 \mathrm{~cm}(p<.001)$ using the Optojump. The Myotest also underestimated peak force by $167 \pm 182 \mathrm{~N}(p<.001)$. Compared to force impulse algorithm, the Myotest displayed less agreement for peak velocity $\left(r^{2}=.245\right)$ and peak power $\left(r^{2}=.557\right)$. Conclusion: Accelerometers are valid and may be used consistently to evaluate countermovement jump height. However, they are not valid, and should neither be used to measure peak force, velocity, or power nor be compared against other methods due to a bias.
\end{abstract}

Keywords: accelerometer, optic timing, force plate, peak force, peak power

\section{Introduction}

The ability to accurately and reliably measure physical performance is vital for testing and monitoring athletic ability. Certain sports may require specific anthropometric or physiological tests, but vertical jump testing is commonly used to measure ballistic leg strength in athletes of many sports. In fact, the increase in popularity of the vertical jump as a performance-monitoring tool has led to the development and use of an assortment of devices that measure or estimate explosive strength variables such as power output, jump height, and force-time curves.

To bring laboratory-based vertical jump testing to the field, portable devices such as linear position transducers, contact mats, optic timing systems, and

\footnotetext{
* Address for correspondence: Vladimír Hojka, Department of Track and Field, Faculty of Physical Education and Sport, Charles University, José Martího 31, 16252 Prague, Czech Republic. E-mail: hojka@ftvs.cuni.cz
}

accelerometers are now used by athletes and coaches. Although position transducers, contact mats, and optic timing systems are capable of measuring jump height (Cronin, Hing, \& Mcnair, 2004; Glatthorn et al., 2011; Hansen, Cronin, \& Newton, 2011; Leard et al., 2007), the advanced capabilities of accelerometers offer a more robust data set that coaches or athletes can use to assess more than just jump height (Crewther et al., 2011; McMaster, Gill, Cronin, \& McGuigan, 2013).

Previous research has determined the validity and reliability of vertical jump height (Casartelli, Müller, \& Maffiuletti, 2010; Castagna et al., 2013) and estimated power output (Comstock et al., 2011) derived from accelerometers, and generally agree that accelerometers offer a valid and reliable method for measuring these variables. However, other variables such as power output and velocity measures are not as valid or reliable (Choukou, Laffaye, \& Taiar, 2014). Although jump height and power output are commonly used as performance measures in athletes, some coaches may also be interested in the role of force production (Choukou 
et al., 2014) during ballistic tasks, as absolute strength levels have been linked to bodyweight sport performance tasks (Spiteri et al., 2015).

Naturally, force plates are considered to be the gold standard for measuring vertical jump performance (Hatze, 1998; Linthorne, 2001; Vanrenterghem, De Clercq, \& Cleven, 2001), but are often costly, difficult to transport, and require specialized computer equipment to collect and analyse data. On the contrary, accelerometers may also be used to estimate force (Crewther et al., 2011; Mauch, Rist, \& Kaelin, 2014) and offer exceptional portability, often without the need for additional equipment other than a mobile phone or laptop computer.

Previous research has shown that accelerometers provide increasingly valid and reliable force and power output data as the external load of a movement increases (Bampouras, Relph, Orme, \& Esformes, 2013; Comstock et al., 2011; Crewther et al., 2011), but there is a lack of research regarding the use of accelerometers during bodyweight movements such as the countermovement jump, which may be more appropriate for sports in which athletes do not have to provide force against an external resistance (e.g. athletics, soccer, basketball, tennis, etc.). Although accelerometers have been shown to be valid and reliable on multiple occasions (Bubanj et al., 2010; Comstock et al., 2011), recent studies have shown that the use of accelerometers usually overestimates flight time compared to force plates or optic timing systems, consequently overestimating jump height (Casartelli et al., 2010; McMaster et al., 2013; Monnet, Decatoire, \& Lacouture, 2014). Even when using force plates, different algorithms may be used to estimate jump height (Linthorne, 2001). Additionally, data regarding force estimates, peak velocity, and peak power during bodyweight tasks, such as the vertical jump, are lacking.

Therefore, the purpose of this study was to assess the intra-trial concurrent validity of 1) explosive strength indicators (e.g., peak velocity, peak force, and peak power) measured with the Myotest compared to a force plate, and 2) vertical jump height obtained from the Myotest compared to a force plate and the Optojump optic timing system. Based on the studies listed above, it was hypothesized that the Myotest would exhibit a systematic bias for all variables compared to the force plate and Optojump.

\section{Methods}

\section{Participants}

Thirty-three physical education students (22 males, 11 females; $178.6 \pm 5.6 \mathrm{~cm} ; 69.3 \pm 6.5 \mathrm{~kg} ; 21.8 \pm 1.7$ years) participated in the study. All participants were physically active, participated in various sport disciplines at the club level, and had previous experience with countermovement jumps. The participants were informed about the aims of the study, procedures, and possible risks associated with participating in the study. All participants were free to withdraw from the experiment at any time without penalty. Informed consent was provided by all participants, and the project was approved by the Ethical Committee of the Faculty of Physical Education and Sport of Charles University.

\section{Procedures}

Participants reported to the laboratory for a single visit. After anthropometric measurements, they performed 6 minutes of jogging and about 4 minutes of standardized dynamic stretching, focusing on the lower limbs. Next, subjects performed 2 sets of 5 practice countermovement jumps at $75 \%$ and $90 \%$ of maximal perceived effort, respectively. Next, participants performed 5 maximal countermovement jumps with their hands on their hips to avoid any artefact movements during the flight phase (Myotest, 2008). After landing from one jump and before starting the next, participants were required to stand upright in a stationary position for at least 1 second to allow accelerometer calibration (Myotest, 2008).

Data were simultaneously measured using three systems (Figure 1): two parallel force plates (FP; Kistler 9281E, Kistler, Winterthur, Switzerland); an optic timing system (OPT; Optojump, Microgate, Bolzano, Italy); and an accelerometer (ACC; Myotest, Myotest SA, Sion, Switzerland). The OPT, FP, and ACC were all used to estimate jump height $(\mathrm{JH})$, each using a different flighttime algorithm. Additionally, the FP and ACC measured peak force, peak velocity, and peak power output.

Each FP measured ground reaction force at a frequency of $800 \mathrm{~Hz}$. For JH estimation, take-off time was defined as the instance when vertical force dropped below $10 \mathrm{~N}$, and landing time was determined when the $10 \mathrm{~N}$ threshold was exceeded upon landing. Peak velocity, peak force, and peak power output were obtained only during the concentric phase of each jump. Instantaneous velocity was estimated using the following equation:

$$
v(t)=\int_{t_{0}}^{t} \frac{\left(F_{\mathrm{v}}(t)-m g\right)}{m} d t
$$

where $v(t)$ is instantaneous velocity, $F_{\mathrm{v}}(t)$ is the instantaneous vertical ground reaction force at time $t, m$ is the participant's body mass, $g$ is gravitational acceleration, and $t_{0}$ is the time of the last sample before $F_{\mathrm{v}}$ fell below $95 \%$ of the participant's bodyweight in Newtons. 


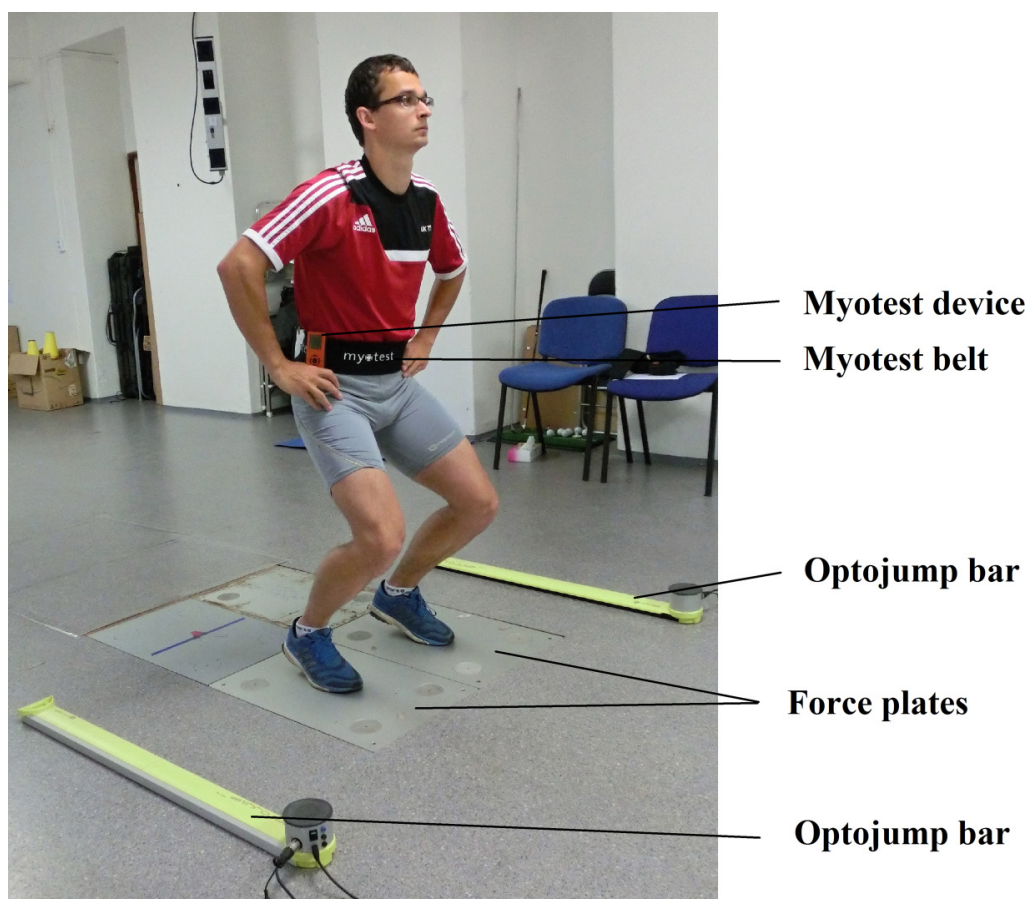

Figure 1. Laboratory measurement settings. Participants performed countermovement jumps standing on two force plates with their hands on the hips. Optojump bars were placed on both sides of force plates, and the Myotest was secured to the waist using the manufacturer's belt.

Instantaneous power output was calculated using the following equation:

$$
P(t)=F_{v}(t) \times v(t)
$$

where $P(t)$ is instantaneous power, $F_{\mathrm{v}}(t)$ is the vertical ground reaction force, and $v(t)$ is estimated instantaneous velocity.

From the FP, JH was calculated using the following equation:

$$
J H_{\mathrm{FP}}=\frac{V_{\mathrm{TO}}^{2}}{2 g}
$$

where $J H_{\mathrm{FP}}$ is jump height derived from the $\mathrm{FP}, V_{\mathrm{TO}}$ is instantaneous velocity at take-off, and $g$ is gravitational acceleration.

The ACC was secured on the right side of the participant, near the centre of mass (Myotest, 2008), using a belt provided by the manufacturer (Figure 1). The sampling frequency of the accelerometer was $200 \mathrm{~Hz}$ (according to the manufacturer's recommendation for countermovement jump testing). Peak velocity (integration of acceleration), force (mass $\times$ acceleration + mass $\times$ gravitational acceleration), and peak power (force $\times$ velocity) output were measured during each take-off. The JH was calculated from flight time, using the following equation:

$$
J H_{\mathrm{ACC}}=\frac{g\left(t_{\mathrm{TD}}-t_{\mathrm{TO}}\right)^{2}}{8}
$$

where $J H_{\mathrm{ACC}}$ is the jump height derived from the ACC, $g$ is gravitational acceleration, $t_{\mathrm{TD}}$ is the time of touchdown, and $t_{\text {то }}$ time of take-off. The algorithm used for flight phase identification in the Myotest software uses the instants of crossing the threshold set to body weight (Figure 2).

The OPT is an optical timing system that consists of a transmitting bar and a receiving bar, placed parallel to each other and on opposite sides of the FP (Figure 1). When standing on the FP, the light emitted from the transmitting bar ( $3 \mathrm{~mm}$ above the ground) does not reach all the sensors on the receiving bar because of obstruction from the feet. When the feet leave the ground during jumping, all of the light from the transmitting bar is received by the receiver bar, and a timer starts to indicate flight time. When the feet break the transmission upon landing ( $3 \mathrm{~mm}$ above the ground), the timer stops, indicating the total flight time. Then, $\mathrm{JH}$ was estimated using the same equation as the ACC, but was determined using the take-off and landing times from the OPT.

The data from the OPT was manually recorded, whereas data from the FP and ACC were exported from the original software (Bioware 5.3.2.9, Kistler, Winterthur, Switzerland; Myotest PRO, Myotest SA, Sion, Switzerland, respectively) and processed in Matlab R14 (MathWorks., Natick, MA, USA). A total of 


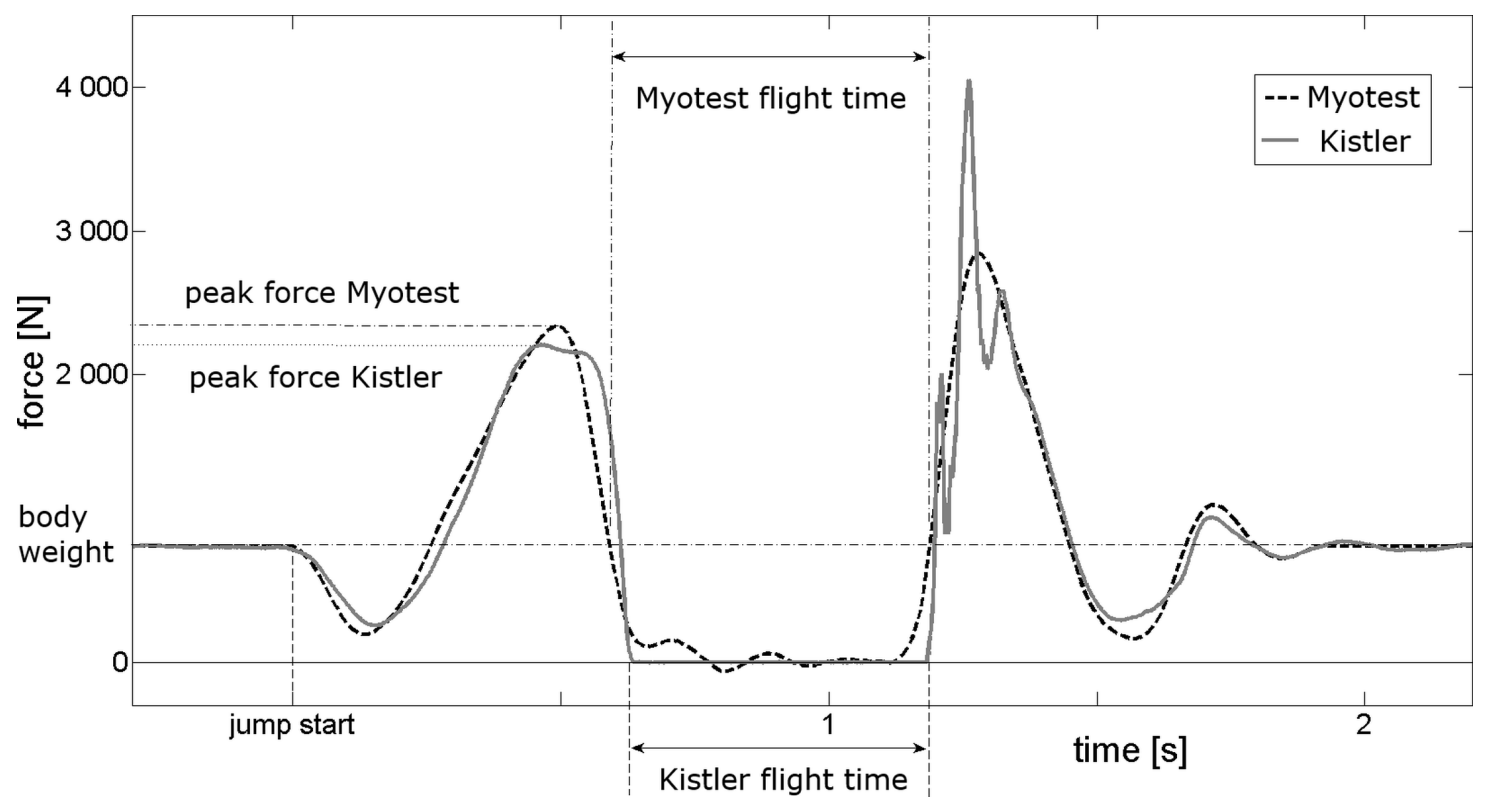

Figure 2. Example of the force-time curve during a counter-movement jump measured using the Myotest accelerometer and Kistler force plate. Graphic shows the flight time of the force plate measurement, registered when the force fell below $10 \mathrm{~N}$; and flight time of the accelerometer measurement, registered when the force was below the subject's bodyweight in Newtons. Although these data were collected at the same time, the temporal synchronization was performed after analysis, only to create this figure to depict the different force curves from each device.

142 out of 165 jumps were analysed, with the remaining 23 jumps unable to be analysed due to errors occurring during data collection (e.g., feet not landing on both force plates, hardware or software malfunction).

\section{Statistical analysis}

Software IBM SPSS Statistics (Version 22; IBM, Armonk, NY, USA) was used for statistical processing. Normality of data distribution was verified using the Kolmogorov-Smirnov test, and homoscedasticity was verified by the Bartlett test. Separate ANOVA with Bonferroni post-hoc tests were used (significance level $\alpha=.05$ ) to determine whether a systematic bias was present between methods for each variable. Effect sizes were calculated using eta squared and can be interpreted as strong $\left(\eta^{2}>.36\right)$, moderate (.04 to .36$)$, and weak $\left(\eta^{2}<.04\right)$ (Cohen, 1988).

Systematic bias (i.e., the general trend of a particular method of measurement to be different in either a positive or negative direction; Atkinson \& Nevill, 1998), was expressed by the mean difference $\pm S D$, with standard error of the mean (Bland \& Altman, 1999).

Pearson correlation ( $r$ with $95 \%$ CI) was used to quantify the relationship of two methods of assessing jump height, peak force, peak velocity and peak power. Linear regression equations were then used to recalculate the variables listed above which were obtained by FP, ACC or OPT. Both regression coefficients (slope and intercept) are reported with 95\% CI. The goodness of fit was evaluated by the coefficient of determination $\left(r^{2}\right)$ and the standard error of estimate (SEE).

\section{Results}

The results are presented as the mean \pm SD. Box plots are shown in Figure 3, that were used to determine whether a significant systematic bias was present for jump height, peak force, peak velocity, and peak power. Table 1 presents the results of systematic bias of methods providing the explosive strength indicators (jump height, peak velocity, peak force, and peak power). Linear regression equations, correlations, and goodness of fit characteristics are presented in Table 2.

\section{Discussion}

This study shows that measurement of peak force during countermovement jumps using ACC results in a significant systematic bias, underestimating peak force by an average of $167 \mathrm{~N}$ compared to a FP. Additionally, and perhaps more importantly, the standard deviation of peak force from the ACC was $187 \mathrm{~N}$, indicating that ACC may under- or overestimate peak force by a large margin. Similarly, peak velocity and peak power output 

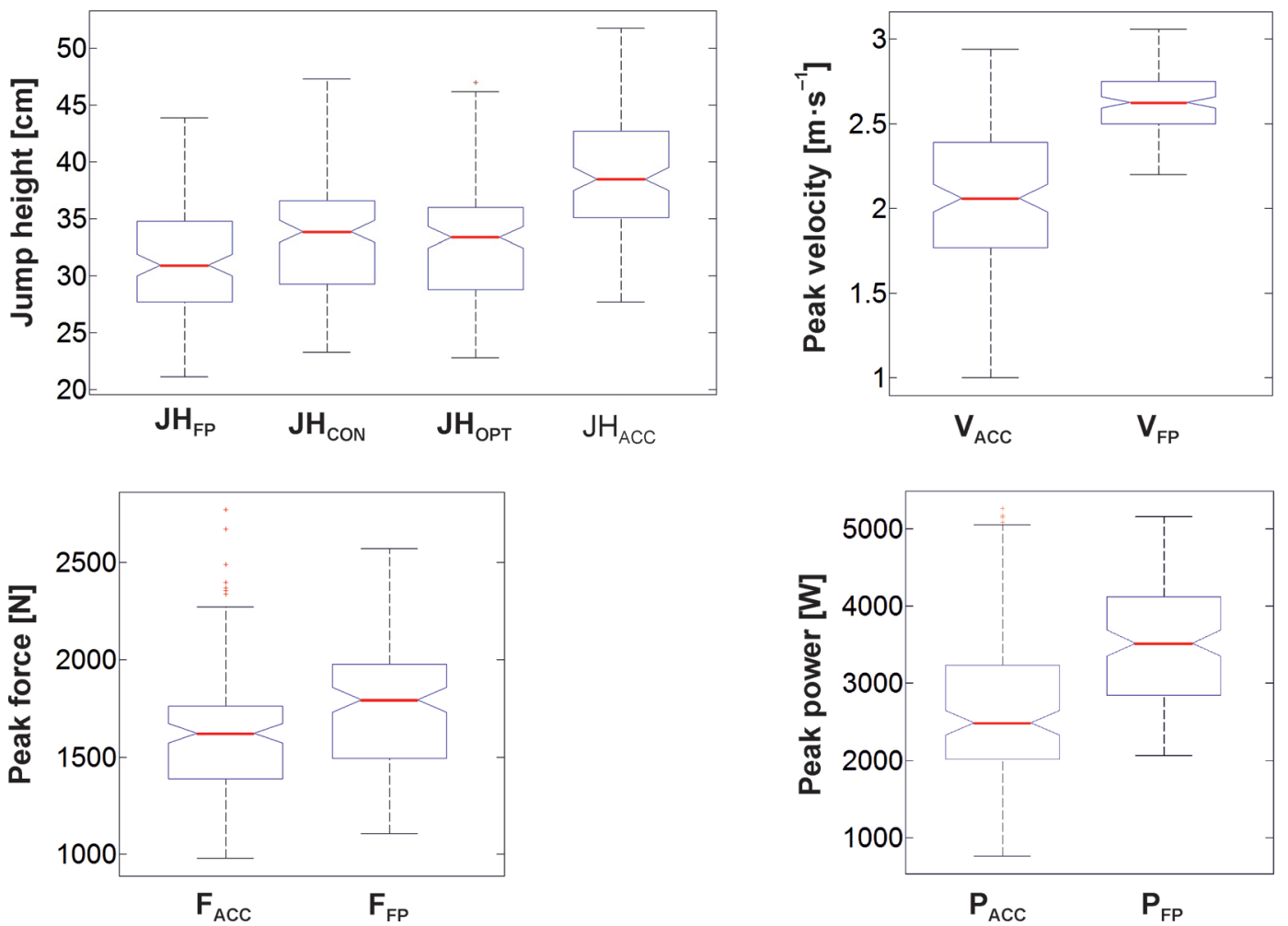

Figure 3. Boxplot of explosive strength indicators. Jump height from force plate flight time $\left(\mathrm{JH}_{\mathrm{FP}}\right)$, optic timing system $\left(\mathrm{JH}_{\mathrm{OPT}}\right)$, accelerometer $\left(\mathrm{JH}_{\mathrm{ACC}}\right)$, and impulse from the force plate $\left(\mathrm{JH}_{\mathrm{CON}}\right)$, peak velocity from accelerometer $\left(\mathrm{V}_{\mathrm{ACC}}\right)$ and force plate $\left(\mathrm{V}_{\mathrm{FP}}\right)$, peak force from accelerometer $\left(\mathrm{F}_{\mathrm{ACC}}\right)$ and force plate $\left(\mathrm{F}_{\mathrm{FP}}\right)$, peak power from accelerometer $\left(\mathrm{P}_{\mathrm{ACC}}\right)$ and force plate $\left(\mathrm{P}_{\mathrm{FP}}\right)$. On each box, the central line is the median, the edges of the box are the 25 th $\left(Q_{1}\right)$ and 75 th $\left(Q_{3}\right)$ percentiles, the whiskers extend to the most extreme data points not considered as outliers within the range from $\mathrm{Q}_{1}-1.5\left(\mathrm{Q}_{3}-\mathrm{Q}_{1}\right)$ to $\mathrm{Q}_{3}+1.5\left(\mathrm{Q}_{3}-\mathrm{Q}_{1}\right)$, and outliers are plotted individually.

Table 1

Systematic bias between methods for determining jump height $(J H)$, peak velocity $(V)$, peak force $(F)$, and peak power (P) using a Myotest accelerometer (ACC), Optojump (OPT), JH from the force plate impulse (FP), and $J H$ from force plate contact time (CON). Effect sizes $\left(\eta^{2}\right)$ and standard errors of the measurement (SEM) are also provided.

\begin{tabular}{lcccc}
\hline Variable & Difference $\pm S D$ & $p$ & $\eta^{2}$ & SEM \\
\hline $\mathrm{JH}_{\mathrm{ACC}}-\mathrm{JH}_{\mathrm{FP}}(\mathrm{cm})$ & $8.0 \pm 2.1$ & $<.001$ & .34 & 0.20 \\
$\mathrm{JH}_{\mathrm{ACC}}-\mathrm{JH}_{\mathrm{OPT}}(\mathrm{cm})$ & $5.9 \pm 2.0$ & $<.001$ & .20 & 0.20 \\
$\mathrm{JH}_{\mathrm{ACC}}-\mathrm{JH}_{\mathrm{CON}}(\mathrm{cm})$ & $5.5 \pm 2.0$ & $<.001$ & .18 & 0.20 \\
$\mathrm{~V}_{\mathrm{ACC}}-\mathrm{V}_{\mathrm{FP}}\left(\mathrm{m} \cdot \mathrm{s}^{-1}\right)$ & $-0.56 \pm 0.37$ & $<.001$ & .41 & 0.03 \\
$\mathrm{~F}_{\mathrm{ACC}}-\mathrm{F}_{\mathrm{FP}}(\mathrm{N})$ & $-167 \pm 182$ & $<.001$ & .06 & 15.0 \\
$\mathrm{P}_{\mathrm{ACC}}-\mathrm{P}_{\mathrm{FP}}(\mathrm{W})$ & $-843 \pm 626$ & $<.001$ & .19 & 52.0 \\
\hline
\end{tabular}

displayed a systematic bias compared to the FP with only moderate correlations ( $r=.49$ to .75 ). As for $\mathrm{JH}$, the data from this study agree with previous research (Casartelli et al., 2010; Choukou et al., 2014; Mauch et al., 2014) in that the ACC and OPT are reliable ( $r=.93$ to .94 ) compared to the FP, but both include a significant systematic bias (Table 1). Therefore, the data from the present study indicate that ACC can be used to measure $\mathrm{JH}$, but includes a systematic bias; and ACC should not be used to measure peak force, peak velocity, or peak power output during unloaded countermovement jumps.

Jump height measured by ACC was significantly higher than jump height calculated from the OPT or FP, 
Table 2

Correlations (r), goodness of fit $\left(r^{2}\right)$, standard error of estimates (SEE) and regression equations for estimating jump height $(J H)$, peak velocity $(V)$, peak force $(F)$, and peak power $(P)$ from a Myotest accelerometer (ACC), force plate $(F P)$, force plate contact time (CON), and Optojump (OPT).

\begin{tabular}{|c|c|c|c|}
\hline Regression equation & $r^{2}$ & $\begin{array}{c}r \\
{[95 \% \mathrm{CI}]} \\
\end{array}$ & $S E E$ \\
\hline $\mathrm{JH}_{\mathrm{FP}}=\left(0.852 * \mathrm{JH}_{\mathrm{ACC}}\right)-2.1$ & .866 & $\begin{array}{c}.93 \\
{[.90, .95]}\end{array}$ & 2.0 \\
\hline $\mathrm{JH}_{\mathrm{OPT}}=\left(0.929 * \mathrm{JH}_{\mathrm{ACC}}\right)-3.1$ & .887 & $\begin{array}{c}.94 \\
{[.92, .96]}\end{array}$ & 1.9 \\
\hline $\mathrm{JH}_{\mathrm{CON}}=\left(0.925 * \mathrm{JH}_{\mathrm{ACC}}\right)-2.6$ & .884 & $\begin{array}{c}.94 \\
{[.92, .96]}\end{array}$ & 2.0 \\
\hline $\mathrm{V}_{\mathrm{FP}}=\left(0.233 * \mathrm{~V}_{\mathrm{ACC}}\right)+2.14$ & .245 & $\begin{array}{c}.49 \\
{[.36, .61]}\end{array}$ & 0.18 \\
\hline $\mathrm{F}_{\mathrm{FP}}=\left(0.8524 * \mathrm{~F}_{\mathrm{ACC}}\right)+406$ & .727 & $\begin{array}{c}.85 \\
{[.80, .89]}\end{array}$ & 176 \\
\hline $\mathrm{P}_{\mathrm{FP}}=\left(0.6072 * \mathrm{P}_{\mathrm{ACC}}\right)+1883$ & .557 & $\begin{array}{c}.75 \\
{[.66, .81]}\end{array}$ & 510 \\
\hline
\end{tabular}

and jump height calculated from flight time was overestimated in comparison with jump height calculated from force impulse. This may be attributed to an asymmetry between the ascending and descending phases of the flight. Since the take-off point occurs with near triple extension and the landing occurs with the hips, knees, and ankles slightly flexed, it increases the total flight time which may artificially increase jump height according to flight time calculations. Additionally, differences in jump height measured by ACC arise from the use of a different flight-time algorithm: while the force plate algorithm considers flight time as the time interval of the unloaded plate (vertical force $<10 \mathrm{~N}$ ), the accelerometer algorithm considers flight time as the time interval when the applied force is less than body weight (Glatthorn et al., 2011; Houel, Dinu, Faury, \& Seyfried, 2011; Pazin, Berjan, Nedeljkovic, Markovic, \& Jaric, 2013). Monnet et al. (2014) proposed an algorithm for determining flight time that considers flight time as the time interval when the exerted force is less than a half of a subject's body weight. However, this algorithm may become unstable in field conditions and lead to wrong results. Our results proved the existence of a systematic bias in jump height estimation using an ACC, which corresponds to recent findings (Casartelli et al., 2010; Castagna et al., 2013; Houel et al., 2011).

The $\mathrm{F}_{\mathrm{ACC}}$ was significantly less than $\mathrm{F}_{\mathrm{FP}}$, but displayed a very good relationship $(r=.85)$, resulting in a systematic bias. However, the bias $S D$ of $182 \mathrm{~N}$ and regression $S E E$ of $176 \mathrm{~N}$ indicate large random errors. Additionally, the coefficient of determination value $\left(r^{2}=.727\right)$ supports the idea of less agreement between $\mathrm{F}_{\mathrm{ACC}}$ and $\mathrm{F}_{\mathrm{FP}}$, meaning $\mathrm{ACC}$ should not be used to measure force during a CMJ. The accuracy of peak force estimation could be increased using the squat jump and place the accelerometer on the bar (Bampouras et al., 2013; Crewther et al., 2011; Mauch et al., 2014), where the accuracy of the ACC has been shown to increase with increasing loads (Crewther et al., 2011). Therefore, we recommend reconsidering the use of ACC to estimate peak force during unloaded vertical jumps.

Peak velocity and peak power consequently are clearly underestimated while using an ACC. As peak velocity uses acceleration (ratio of force and mass) integration, it leads to even larger errors than those presented in the case of peak force, also resulting in much less agreement $(r=.49)$. Therefore, we cannot recommend using an ACC to estimate peak velocity or calculate jump height from movement velocity. Our results correspond to recent findings (McMaster et al., 2013), which also reported a moderate correlation of peak velocity estimate and large error in squat jump.

Similarly, peak power bias was influenced by both, velocity and force. However, agreement of the ACC and FP in peak power estimate was better than in the case of peak velocity. Recent squat jump studies (Comstock et al., 2011; Crewther et al., 2011) presented correlations of ACC and FP between .49-.93. The accuracy is increased with increasing load on the bar, which may lead to the conclusion to recommended using an ACC to estimate individual maximum peak power against heavy loads.

The source of the ACC's inaccuracy during CMJ appears to be its imperfection in estimating centre of mass. The idea to place the accelerometer as close as 
possible to the centre of mass of a system (waist) should be correct (Houel, Faury, \& Seyfried, 2013). However, when the accelerometer is placed on a barbell, it shows better agreement with other methods not only in jump height, but also in peak force, peak velocity, and peak power (Comstock et al., 2011; Crewther et al., 2011; Giroux, Rabita, Chollet, \& Guilhem, 2015; Houel et al., 2011; McMaster et al., 2013). Furthermore, the validity of ACC increases with heavier load, because it moves the centre of gravity closer to the device and minimizes the possibility of artefact movements, which also may be explained by the ACC being fixed to a rigid frame. The solution to increase the accuracy of explosive strength indicators may be to execute CMJs with a very light bar on the shoulders and place the ACC on it (McMaster et al., 2013), but the effects of this method on CMJ height remain unknown. The remaining problem of using an ACC during $\mathrm{CMJ}$ is its inability to precisely determine the instant of the transition from eccentric to concentric phases as well as the point of take-off due to inertial forces acting on the device. These forces manifest themselves as oscillation despite wearing a perfectly tight belt. Oscillation could be minimized by attaching the device directly on a rigid bar. Additionally the jump height calculated by an ACC might be affected by increased asymmetry of flight phase, similar to other methods that use flight time to estimate jump height (Castagna et al., 2013). Due to the heterogeneity of our sample, it is possible that future research may determine whether the same results will be achieved if using more homogeneous groups of athletes such as elite jumpers and elite sprinters.

\section{Conclusion}

The use of ACC to evaluate countermovement jump performance is possible, but it systematically overestimates jump height compared to other methods. Therefore, it may be used consistently to evaluate an athlete's performance, but should not be used for academic research purposes. It is also possible to estimate peak force with an ACC, but using an ACC would likely provide less agreement with the gold standard, and the magnitude of the random error for peak force should be considered. Using an ACC during a CMJ, peak velocity showed the least agreement and largest error, neither of which were optimized after recalculation. Therefore, we suggest that an ACC can be used to measure jump height within an individual over time but should not be used to estimate peak velocity or peak power output during the CMJ.

\section{Acknowledgments}

This work was supported by the Czech Science Foundation (grant number 16-2179S) and research program of Charles University Progres Q41.

\section{Conflict of interest}

There were no conflicts of interest.

\section{References}

Atkinson, G., \& Nevill, A. M. (1998). Statistical methods for assessing measurement error (reliability) in variables relevant to sports medicine. Sports Medicine, 26, 217-238.

Bampouras, T. M., Relph, N. S., Orme, D., \& Esformes, J. I. (2013). Validity and reliability of the Myotest Pro wireless accelerometer in squat jumps. Isokinetics and Exercise Science, 21, 101-105.

Bland, J. M., \& Altman, D. G. (1999). Measuring agreement in method comparison studies. Statistical Methods in Medical Research, 8, 135-160.

Bubanj, S., Stanković, R., Bubanj, R., Bojić, I., Đinđić, B., \& Dimić, A. (2010). Reliability of Myotest tested by a countermovement jump. Acta Kinesiologica, 4(2), 46-48.

Casartelli, N., Müller, R., \& Maffiuletti, N. A. (2010). Validity and reliability of the Myotest accelerometric system for the assessment of vertical jump height. Journal of Strength and Conditioning Research, 24, 3186-3193.

Castagna, C., Ganzetti, M., Ditroilo, M., Giovannelli, M., Rocchetti, A., \& Manzi, V. (2013). Concurrent validity of vertical jump performance assessment systems. Journal of Strength and Conditioning Research, 27, 761-768.

Choukou, M. A., Laffaye, G., \& Taiar, R. (2014). Reliability and validity of an accelerometric system for assessing vertical jumping performance. Biology of Sport, 31, 55-62.

Cohen, J. (1988). Statistical power analysis for the behavioral sciences (2nd ed.). Hillsdale, NJ: Erlbaum.

Comstock, B. A., Solomon-Hill, G., Flanagan, S. D., Earp, J. E., Luk, H. Y., Dobbins, K. A., ... Kraemer, W. J. (2011). Validity of the Myotest ${ }^{\circledR}$ in measuring force and power production in the squat and bench press. Journal of Strength and Conditioning Research, 25, 2293-2297.

Crewther, B. T., Kilduff, L. P., Cunningham, D. J., Cook, C., Owen, N., \& Yang, G. Z. (2011). Validating two systems for estimating force and power. International Journal of Sports Medicine, 32, 254-258.

Cronin, J. B., Hing, R. D., \& Mcnair, P. J. (2004). Reliability and validity of a linear position transducer for measuring jump performance. Journal of Strength and Conditioning Research, 18, 590-593.

Giroux, C., Rabita, G., Chollet, D., \& Guilhem, G. (2015). What is the best method for assessing lower limb forcevelocity relationship? International Journal of Sports Medicine, 36, 143-149.

Glatthorn, J. F., Gouge, S., Nussbaumer, S., Stauffacher, S., Impellizzeri, F. M., \& Maffiuletti, N. A. (2011). Validity and reliability of optojump photoelectric cells for 
estimating vertical jump height. Journal of Strength and Conditioning Research, 25, 556-560.

Hansen, K. T., Cronin, J. B., \& Newton, M. J. (2011). The reliability of linear position transducer and force plate measurement of explosive force-time variables during a loaded jump squat in elite athletes. Journal of Strength and Conditioning Research, 25, 1447-1456.

Hatze, H. (1998). Validity and reliability of methods for testing vertical jumping performance. Journal of Applied Biomechanics, 14, 127-140.

Houel, N., Dinu, D., Faury, A., \& Seyfried, D. (2011). Accuracy and reliability of the Myotest Pro system to evaluate a squat jump. Procedia Engineering, 13, 434-438.

Houel, N., Faury, A., \& Seyfried, D. (2013). Influence of the point of attachment of two accelerometers on the assessment of squat jump performances. International Journal of Computer Science in Sport, 12, 1-17.

Leard, J. S., Cirillo, M. A., Katsnelson, E., Kimiatek, D. A., Miller, T. W., Trebincevic, K., \& Garbalosa, J. C. (2007). Validity of two alternative systems for measuring vertical jump height. Journal of Strength and Conditioning Research, 21, 1296-1299.

Linthorne, N. P. (2001). Analysis of standing vertical jumps using a force platform. American Journal of Physics, 69, 1198-1204.

Mauch, M., Rist, H. J., \& Kaelin, X. (2014). Reliability and validity of two measurement systems in the quantification of jump performance. Schweizerische Zeitschrift fur Sportmedizin und Sporttraumatologie, 62, 57-63.

McMaster, D. T. W., Gill, N. D., Cronin, J. B., \& McGuigan, M. R. (2013). Is wireless accelerometry a viable measurement system for assessing vertical jump performance? Sports Technology, 6, 86-96.

Monnet, T., Decatoire, A., \& Lacouture, P. (2014). Comparison of algorithms to determine jump height and flight time from body mounted accelerometers. Sports Engineering, 17, 249-259.

Myotest. (2008). Myotest quick start guide. Available from http://www.hssports.co.uk/media/attachments/myotestmanual.pdf

Pazin, N., Berjan, B., Nedeljkovic, A., Markovic, G., \& Jaric, S. (2013). Power output in vertical jumps: Does optimum loading depend on activity profiles? European Journal of Applied Physiology, 113, 577-589.

Spiteri, T., Newton, R. U., Binetti, M., Hart, N. H., Sheppard, J. M., \& Nimphius, S. (2015). Mechanical determinants of faster change of direction and agility performance in female basketball athletes. Journal of Strength and Conditioning Research, 29, 2205-2214.

Vanrenterghem, J., De Clercq, D., \& Cleven, P. V. (2001). Necessary precautions in measuring correct vertical jumping height by means of force plate measurements. Ergonomics, 44, 814-818. 